\title{
Radiation exposure in cardiac multislice spiral computed tomography (MSCT)
}

\author{
Annick C Weustink and Pim J de Feyter*
}

\begin{abstract}
Address: Erasmus Medical Center, Department of Cardiology and Radiology, PO Box 2040, 3000 CA, Rotterdam, The Netherlands
*Corresponding author: Pim de Feyter (p.j.defeyter@erasmusmc.nl)

FI000 Medicine Reports 2009, I:I (doi: 10.34I0/MI-I)

The electronic version of this article is the complete one and can be found at: http://FI000.com/Reports/Medicine/content/l/I

Abstract

Computed tomographic (CT) imaging involves exposure to ionizing radiation, with a consequent potential risk to the patient. Here we review the technical factors that affect the radiation dose in cardiac CT diagnostic procedures, the parameters that are used to measure and compare radiation doses, the magnitude of radiation exposure, and how to efficiently reduce it.
\end{abstract}

\section{Introduction and context}

The use of computed tomographic (CT) diagnostic procedures in cardiology is steadily increasing and is expected to grow even more if the technique evolves to become a primary diagnostic modality for coronary artery disease. As CT involves the use of ionizing radiation in the form of X-rays, the issue of radiation exposure in coronary imaging by multislice spiral computed tomography (MSCT) has attracted considerable attention. The risks and benefits of each CT coronary angiogram (CTCA) should be carefully weighed, and the ALARA principle (as low as reasonably achievable) to reduce radiation dose to the patient should always be respected. It is essential that the ordering physicians and the technicians who perform CT examinations have adequate knowledge of the radiation exposure of the procedures and understand how to minimize the dosage while preserving the quality of the diagnostic image. Here we review the technical factors that affect the radiation dose, the parameters that are used to measure and compare radiation doses, the magnitude of radiation exposure and how to efficiently reduce it.

\section{Radiation-dose terminology}

Radiation exposure in CT is generally quantified by the tube-current-time product or the mAs-value. It does not, however, directly quantify the absorbed radiation dose. Absorbed dose is the amount of radiation energy per unit mass tissue deposited in a patient's body by X-ray photons. The most useful parameters for comparing radiation doses are the computed tomography dose index $\left(\mathrm{CTDI}_{\mathrm{vol}}\right)$, the dose-length product (DLP) and the effective dose (E) (Table 1).

The CTDI ${ }_{\mathrm{vol}}[$ measured in units of grays (Gy)] represents the average radiation dose in the $x, y, z$ directions and estimates the average radiation within the irradiated volume of one CT acquisition. The value of $\mathrm{CTDI}_{\mathrm{vol}}$ can be obtained by standardized phantom measurements with an ionization chamber. It compensates for the overlap between slices, by normalizing to the pitch (pitch is the table advancement per rotation divided by the collimated detector width) CTDI $_{\mathrm{vol}}$ enables ready comparison between the radiation doses from different CT scanners. The DLP represents the integrated radiation dose over all slices from an entire CT examination. The DLP is calculated as DLP $=$ CTDI $_{\mathrm{vol}} \mathrm{x}$ scan length.

The effective dose (E) reflects the risk of potential biological injury of radiation, which depends on the tissue that is exposed. Biological risks include deterministic effects (skin burns, and so on) and stochastic effects (carcinogenesis). A good estimation of effective dose can be obtained from $\mathrm{E}=k \times \mathrm{DLP}$, where $k$ is a conversion coefficient which depends on the body region that is scanned; for the chest $k$ is $0.017 \mathrm{mSv} \mathrm{x}$ 
Table I. Parameters of radiation dose

\begin{tabular}{|c|c|c|}
\hline Parameter & What it represents & SI unit \\
\hline $\mathrm{CT}$ dose index $\left(\mathrm{CTDI} \mathrm{I}_{\mathrm{vol}}\right)$ & $\begin{array}{l}\text { Mean absorbed radiation dose } \\
\text { over total volume scanned }\end{array}$ & Gray (Gy) \\
\hline $\begin{array}{l}\text { Dose-length product } \\
\text { (DLP) }\end{array}$ & Overall dose per scan & $\mathrm{mG} y \times \mathrm{cm}$ \\
\hline Effective dose (E) & Biological effect & Sievert (Sv) \\
\hline
\end{tabular}

$\mathrm{mGy}^{-1} \mathrm{x} \mathrm{cm}^{-1}$. The effective dose allows for a crude comparison between different CT scanners and scan protocols, but is only a rough estimate of the true risk. The latter should be obtained from patient-specific organ doses and risk factors. Here, $\mathrm{E}$ is calculated as the weighted mean of relevant organ values according to the International Commission of Radiological Protection [1]. In cardiac CT the organs receiving the highest doses are the female breasts, lungs, liver and esophagus.

\section{Cardiac CT examination and dose reduction}

Radiation exposure varies with types of CT scanner and scan protocols for cardiac examinations. Variables that play a role in radiation exposure and measures to minimize the radiation exposure are listed in Table 2. Following the ALARA principle, all measures should be taken to reduce radiation exposure to a minimum while preserving diagnostic-quality (rather than esthetic) images. Obviously, the number of investigations is important. The justification for referring a patient for a CT scan should include a careful balancing of the expected benefits of information provided and the (long-term) risk.

Table 2. Variables associated with radiation exposure

\begin{tabular}{ll}
\hline Variable & Measures to minimize radiation \\
\hline Number of CT scans & $\begin{array}{l}\text { Alternative diagnostic modality } \\
\text { Avoid repeat scans } \\
\text { Justification of CT scan (avoid young age) }\end{array}$ \\
$\begin{array}{l}\text { Tube current (mA) } \\
\text { Tube voltage (kV) }\end{array}$ & Optimize settings according to patient BMI \\
$\begin{array}{l}\text { Tube current } \\
\text { modulation } \\
\text { ECG-controlled }\end{array}$ & Adjust to patient's heart rate \\
$\begin{array}{l}\text { Angular-longitudinal } \\
\text { Scan length }\end{array}$ & $\begin{array}{l}\text { Adjust data acquisition to optimal cardiac } \\
\text { phase (ECG pulsing window) } \\
\text { Adjust to patient attenuation profile } \\
\text { Prospective gating axial } \\
\text { Retrospective gating } \\
\text { helical (RGH) }\end{array}$ \\
\hline
\end{tabular}

Figure I. Comparison of different CT scan protocols

(a)

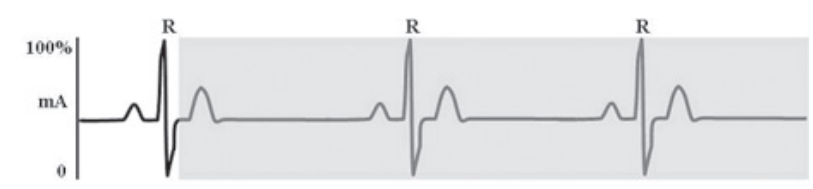

(b)

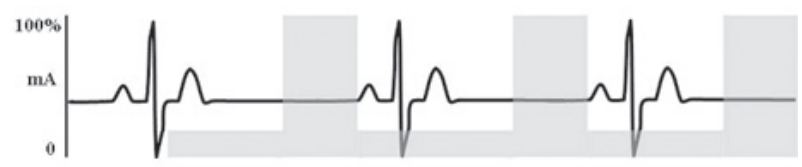

(c)

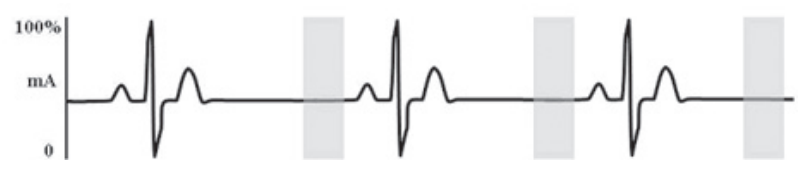

Radiation exposure is represented by the gray shade. (a) Helical CT coronary angiography (CTCA) without ECG tube modulation.

(b) Retrospectively gated helical CTCA with ECG tube modulation (E $\approx 1020 \mathrm{mSv}$ in 64-slice CT). (c) Prospectively gated axial CTCA or step-and-shoot algorithm $(E \approx 23 \mathrm{mSv}$ in 64-slice $C T)$.

A CT scan should not be performed if the same diagnostic information can be obtained by an alternative modality that does not use ionizing radiation. Of particular importance, always avoid unintentional repeat examinations.

Figure 2. Example of retrospectively gated dual-source CT coronary angiography

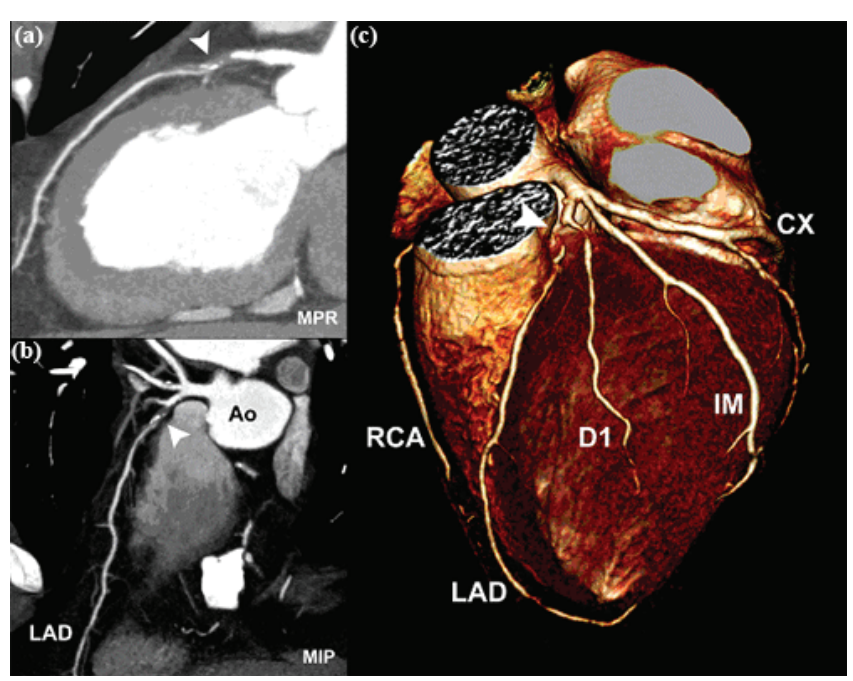

Heart rate 64 beats/minute; pitch 0.28 ; tube voltage $120 \mathrm{kV}$; peak tube current $625 \mathrm{~mA} /$ tube; and ECG tube current modulation. (a) The curved multiplanar projection (MPR), (b) the maximum intensity projection (MIP) and (c) the colored-volume-rendered image show a subtotal occlusion (marked by a white arrowhead) of the proximal left anterior descending (LAD) artery. Effective dose, $7.2 \mathrm{mSv}$. Ao, aorta; CX, left circumflex artery; DI, first diagonal; IM, intermediate branch; RCA, right coronary artery. 
Image noise increases and image quality decreases if the number of photons that is used for image reconstruction decreases. The number of X-ray photons generated by the $\mathrm{X}$-ray tube per reconstructed slice depends on tube current $(\mathrm{mA})$, tube voltage $(\mathrm{kV})$ and pitch, which can be adjusted to achieve diagnostic-image quality with the lowest settings. Improved spatial resolution with newergeneration 64-slice scanners requires an increase in tube current. Lower mA settings can be used in slim patients. Radiation dose varies with the square of the voltage (in kilovolts), and image contrast improves by decreasing tube voltage in patients with low body mass index (BMI). This approach has resulted in dose reductions of up to $88 \%$ in cardiac CT examinations [2]. However, low-voltage settings are less preferable in CT coronary angiography as image noise also increases, resulting in degradation of the coronary images. The pitch (which determines the degree of slice overlap) should be selected to obtain optimal image quality and should be adjusted to heart rate, if possible. The scan length should be individualized to the size of the heart. Most cardiac CT scans are performed using retrospectively gated helical (RGH) data acquisition. With RGH, the patient moves through the gantry at a constant speed, and data are acquired and available throughout the cardiac cycle. The tube current can be modulated during scanning by selecting a pulsing window according to the electrocardiogram (for example, during end-diastole) during which the patient is exposed to maximum radiation, while tube current is lowered during the remaining cardiac phases. This can reduce overall effective dose by $30-50 \%[2,3]$ and is most effective in the case of low heart rates.

\section{Recent advances}

Another technique recently introduced for CT coronary angiography is prospectively gated axial (PGA) data acquisition. This technique uses a step-and-shoot mode: the table is stationary during data acquisition and then moves to the next position for the second scan. X-ray generation is switched off between two consecutive scans, resulting in an overall low dose to the patient (1.1-3.0 mSv) [4]. The downside of this technique is that it is only applicable in patients with low heart rates (prescan beta-blockers are required for patients with higher heart rates) and regular, very stable heart rhythms. Estimates of the effective dose for conventional coronary angiography, cardiac nuclear imaging, and various cardiac CT scan protocols are listed in Table 3.

\section{Radiation exposure and risk estimation}

Cardiac CT examination is associated with a (low) lifetime-attributable risk (LAR) of incidence of and mortality from cancer. The LAR estimates of cancer
Table 3. Estimates of effective dose (E)

\begin{tabular}{lcc}
\hline & $\begin{array}{c}\text { E range in mSv } \\
\text { (mean) }\end{array}$ & $\begin{array}{c}\text { ECG tube } \\
\text { modulation }\end{array}$ \\
\hline $\begin{array}{l}\text { Average background radiation (United } \\
\text { States) }\end{array}$ & $1.0-10(3.6)$ & - \\
Conventional coronary angiography & $3.1-21.8(5.6)$ & - \\
Nuclear MPI studies & $2.2-31.5$ & - \\
Ca scoring (retrospectively gated & $1.0-6.2$ & - \\
helical) & & \\
Ca scoring (prospectively gated axial) & $1.0-3.0$ & - \\
CTCA (retrospectively gated helical) & & \\
16-slice & $5.7-13$ & No \\
16-slice & $2.9-5.6$ & Yes \\
64-slice & $9.4-21.4$ & Yes \\
64-slice dual source & $7.8-16.9$ & Yes \\
320-slice & $10.1-18.1$ & No \\
CTCA (prospectively gated axial) & & \\
64-slice & $0.75-6.7(2.8)$ & - \\
320-slice & $4.9-16.5$ & - \\
\end{tabular}

Data from [9-19].

Table 4. Lifetime-attributable risk of cancer following 64-slice CT coronary angiography

\begin{tabular}{|c|c|c|c|c|}
\hline $\begin{array}{l}\text { Age } \\
\text { (years) }\end{array}$ & Standard CT & $\begin{array}{l}\text { Tube current } \\
\text { modulation }\end{array}$ & Standard CT & $\begin{array}{l}\text { Tube current } \\
\text { modulation }\end{array}$ \\
\hline & Female & Female & Male & Male \\
\hline 40 & I in 284 & I in 435 & I in 1007 & I in 1534 \\
\hline 60 & I in 466 & 1 in 715 & $I$ in $|24|$ & 1 in 1911 \\
\hline 80 & 1 in 1388 & I in 2082 & 1 in 1284 & $I$ in 1834 \\
\hline
\end{tabular}

Data from [7].

have been derived from studies of atomic-bomb survivors (those who received low doses of radiation ranging from 5 to $150 \mathrm{mSv}$, mean dose $40 \mathrm{mSv}$ ) [5] and a large-scale study of 400,000 radiation workers in the nuclear industry (receiving a dose of approximately $20 \mathrm{mSv}$ ) [6]. These studies revealed a significant association between radiation dose and mortality from cancer. Einstein et al. [7] showed that 64-slice cardiac CTCA is associated with a non-negligible LAR of cancer and, most importantly, that the LAR estimates of cancer incidence attached to CT examinations are highly dependent on the age and gender of the patient (Table 4 ), with younger patients and females having a higher LAR of cancer incidence. The risk can, however, be significantly reduced using dose-reduction techniques.

\section{Implications for clinical practice}

Cardiac CT examinations are, inevitably, associated with a certain radiation-induced risk of cancer, which is age and gender dependent. The risk is higher in younger patients and women. The risk of cancer must be decreased by minimizing radiation exposure to as low 
as possible while maintaining diagnostic image quality. The ordering physician should be aware of this cancer risk and should carefully consider the potential diagnostic benefits of the investigation, which should outweigh the associated risk of cancer. The technician performing the CT scan should have a thorough knowledge of the CT scanner specifications and should select a scan protocol that generates images with a minimal radiation dose and the required image quality. But most importantly, at all times avoid cardiac CT examinations that are not justified by medical need [8].

\section{Abbreviations}

ALARA, as low as reasonably achievable; BMI, body mass index; CT, computed tomographic; CTCA, computed tomographic coronary angiogram; $\mathrm{CTDI}_{\mathrm{vol}}$, computed tomography dose index; DLP, dose-length product; $\mathrm{E}$, effective dose; LAR, lifetime-attributable risk; MSCT, multislice spiral computed tomography; PGA, prospectively gated axial; RGH, respectively gated helical.

\section{Competing interests}

The authors declare that they have no competing interests.

\section{Acknowledgements}

The authors would like to thank Marcel van Straten, Department of Radiology, Erasmus Medical Center, for stimulating discussions and contributions to this review.

\section{References}

I. 1990 Recommendations of the International Commission on Radiological Protection (IRCP Publication 60). Ann ICRP I99I, 21: I 305-I0.

2. Abada HT, Larchez C, Daoud B, Sigal-Cinqualbre A, Paul JF: MDCT of the coronary arteries: feasibility of low-dose CT with ECGpulsed tube current modulation to reduce radiation dose. $\mathrm{Am}$ J Roentgenol 2006, I86(Suppl 2):S387-90.

3. Jakobs TF, Becker CR, Ohnesorge B, Flohr T, Suess C, Schoepf UJ, Reiser MF: Multislice helical CT of the heart with retrospective ECG gating: reduction of radiation exposure by ECGcontrolled tube current modulation. Eur Radiol 2002, I 2:1081-6.

4. Husmann L, Valenta I, Gaemperli O, Adda O, Treyer V, Wyss CA, Veit-Haibach P, Tatsugami F, von Schulthess GK, Kaufmann PA: Feasibility of low-dose coronary CT angiography: first experience with prospective ECG-gating. Eur Heart J 2008, 29:19|-7.

FI000 Factor 6.0 Must Read Evaluated by Pim de Feyter 7 Jul 2008

5. Board on Radiation Effects Research: Health Risks from Exposure to Low Levels of lonizing Radiation: BEIR VII. Washington, DC: National Academies Press, 2005.

6. Cardis E, Vrijheid M, Blettner M, Gilbert E, Hakama M, Hill C, Howe G, Kaldor J, Muirhead CR, Schubauer-Berigan M, Yoshimura T, Bermann F, Cowper G, Fix J, Hacker C, Heinmiller B, Marshall M, Thierry-Chef I, Utterback D, Ahn YO, Amoros E, Ashmore P, Auvinen A, Bae JM, Bernar J, Biau A, Combalot E, Deboodt P, Diez Sacristan A, Eklöf M, et al. The 15-country collaborative study of cancer risk among radiation workers in the nuclear industry: estimates of radiation-related cancer risks. Radiat Res 2007 167:396-416.

7. Einstein AJ, Henzlova MJ, Rajagopalan S: Estimating risk of cancer associated with radiation exposure from 64-slice computed tomography coronary angiography. JAMA 2007, 298:317-23.

Changes Clinical Practice

FI000 Factor 6.4 Must Read

Evaluated by Eugenio Picano 17 Aug 2007, Paul Stein 24 Dec 2007

8. Brenner DJ, Hall EJ: Computed tomography - an increasing source of radiation exposure. $N$ Engl J Med 2007, 357:2277-84.

9. Einstein AJ, Moser KW, Thompson RC, Cerqueira MD, Henzlova MJ: Radiation dose from cardiac imaging. Circulation 2007, I 16:1290-305.

10. Hunold P, Vogt FM, Schmermund A, Debatin JF, Kerkhoff G, Budde T, Erbel R, Ewen K, Barkhausen J: Radiation exposure during cardiac CT: effective dose at multi-detector row $\mathrm{CT}$ and electron-beam CT. Radiology 2003, 226: 145-52.

II. Flohr TG, Schoepf UJ, Kuettner A, Halliburton S, Bruder H, Suess C, Schmidt B, Hofmann L, Yucel EK, Schaller S, Ohnesorge BM: Advances in cardiac imaging with 16-section CT systems. Acad Radiol 2003, 10:386-40I.

12. Morin RL, Gerber TC, McCollough $\mathrm{CH}$ : Radiation dose in computed tomography of the heart. Circulation 2003, 107:917-22.

13. Trabold T, Buchgeister M, Küttner A, Heuschmid M, Kopp AF, Schröder $S$, Claussen CD: Estimation of radiation exposure in 16-detector row computed tomography of the heart with retrospective ECG-gating. Rofo 2003, I75:105I-55.

14. Hausleiter J, Meyer T, Hadamitzky M, Huber E, Zankl M, Martinoff S, Kastrati A, Schömig A: Radiation dose estimates from cardiac multislice computed tomography in daily practice: impact of different scanning protocols on effective dose estimates. Circulation 2006, II3:1305-10.

15. Mollet NR, Cademartiri F, van Mieghem CA, Runza G, McFadden EP, Baks T, Serruys PW, Krestin GP, de Feyter PJ: High-resolution spiral computed tomography coronary angiography in patients referred for diagnostic conventional coronary angiography. Circulation 2005, I I 2:23 I 8-23.

FI000 Factor 3.0 Recommended

Evaluated by Stephan Achenbach 26 Jan 2006

16. Weustink AC, Meijboom WB, Mollet NR, Otsuka M, Pugliese F, van Mieghem C, Malago R, van Pelt N, Dijkshoorn ML, Cademartiri F, Krestin GP, de Feyter PJ: Reliable high-speed coronary computed tomography in symptomatic patients. J Am Coll Cardiol 2007, 50:786-94.

17. Ropers U, Karakaya S, Wechsel M, Anders K, Ropers D, Kuettner A, Daniel WG, Kalender W, Bautz W, Achenbach S: Randomized comparison of dual source computed tomography and 64-slice multi-detector computed tomography for the detection of coronary artery stenoses. [Abstract] Circulation 2006, I 1 4:448.

18. Earls JP, Berman EL, Urban BA, Curry CA, Lane JL, Jennings RS, McCulloch CC, Hsieh J, Londt JH: Prospectively gated transverse coronary CT angiography versus retrospectively gated helical technique. Radiology 2008, 246:742-53.

Changes Clinical Practice

FI000 Factor 6.0 Must Read

Evaluated by Stephan Achenbach 26 Mar 2008

19. Rybicki FJ, Otero HJ, Steigner ML, Vorobiof G, Nallamshetty L, Mitsouras D, Ersoy H, Mather RT, Judy PF, Cai T, Coyner K, Schultz K, Whitmore AG, Di Carli MF: Initial evaluation of coronary images from 320-detector row computed tomography. Int J Cardiovasc Imaging 2008, 24:535-46. 